\title{
Espacio político y reconocimiento patrimonial del territorio por la Unesco: el protagonismo de los estados y su papel en la distribución de los bienes reconocidos en sus listados y redes ${ }^{1}$
}

\author{
Political space and heritage recognition of territory by \\ Unesco: the prominence of states and their role in the \\ distribution of recognized properties in its lists and networks
}

\author{
Rocío Silva Pérez ${ }^{2}$ (1) y Víctor Fernández Salinas ${ }^{3}$ (1)
}

\section{RESUMEN}

La consideración del territorio en los programas de sesgo patrimonial de la Unesco es un hecho poco estudiado. En este artículo, se parte de la doble acepción del concepto de territorio: el político y administrativo frente al físico y cultural; y se mantiene como hipótesis la prelación del primero sobre el segundo en el marco de los programas patrimoniales territoriales de la Unesco. Para sustentar esto, se revisan los programas auspiciados por la Unesco que toman al territorio como referente directo, delimitado y expresado a través de cartografía precisa. Se propone como innovación analizar estos programas de forma simultánea para determinar la relación que establecen entre la dimensión política y la realidad física y cultural. Como resultado, se explicita el papel desenfocado del territorio manejado por la Unesco que, por la capacidad socioeconómica de los Estados y sus presiones políticas, genera listados de bienes reconocidos por esta organización desequilibrados y poco adaptados a las características reales del planeta y de sus regiones. La conclusión principal se centra en la necesidad de reforzar la perspectiva espacial, tanto en los análisis previos para la valoración de los bienes patrimoniales, como en la determinación de sus delimitaciones $y$, sobre todo, para activar estos bienes como factores de desarrollo.

Palabras clave: Unesco, Humedales Ramsar, Reservas de la Biosfera, Patrimonio Mundial, Geoparques Globales.

\begin{abstract}
The territorial consideration in Unesco's property programs is a little studied topic. In this paper, it is started from the double mining of the territory concept: the political and administrative one versus the physical and cultural one; and it is supposed the priority of the first mining over the second in the framework of Unesco's territorial heritage programs. To support this, it is reviewed the programs sponsored by Unesco that take territory as a direct reference, delimited and expressed through precise mapping. It is proposed, as an innovation, to analyze these programs simultaneously to determine the relationship established between the political dimension and the physical and cultural reality. As a result, the unfocused role of the territory managed by Unesco is explained. This organization, due to the different socio-economic capacity of the States and their political pressures, creates unbalancced lists of properties no well adapted to the real characteristics of the planet and its regions. The main conclusion focuses on the need to reinforce the spatial perspective in the previous analyzes for the valuation of heritage properties, to determinate their delimitations and, above all, to activate these properties as development factors.
\end{abstract}

Keywords: Unesco, Wetlands Ramsar, Biosphere Reserves, World Heritage, Global Geoparks. 
El territorio se ha convertido en un referente básico del patrimonio durante los últimos decenios, tanto en lo que respecta a su identificación y reconocimiento, como a su tutela. No obstante, su incorporación al acervo patrimonial ha sido balbuceante y asimétrica. Del territorio contenedor de bienes patrimoniales, que es la lógica subyacente en las leyes y cartas internacionales, se ha avanzado a la consideración del territorio como bien patrimonial con categoría sustantiva propia (paisajes, itinerarios culturales, etc.). Ello se ha producido en el marco de profundas transformaciones en el entendimiento de los bienes patrimoniales, considerados hoy base de identidad y activo para el desarrollo de los territorios (Silva Pérez \& Fernández Salinas, 2017). Además, el carácter del territorio como receptor de iniciativas económicas aviva el interés de los territorios y sus agentes por acrecentar la presencia de su patrimonio en registros oficiales que raya la obsesión en el caso de programas como la Lista del Patrimonio Mundial. De ello deriva un papel del territorio en el mundo del patrimonio poco considerado hasta ahora: el de origen de propuestas de bienes a listados patrimoniales y, en estrecha relación con ello, el del territorio como condicionante para la aceptación de estos bienes en dichos registros.

La Unesco, como referente de prestigio internacional en la materia, ha desempeñado un papel clave en esos cambios, aunque no siempre los ha liderado, y ha coadyuvado a la importancia emergente de la dimensión territorial del patrimonio por varias vías: a) favoreciendo la aproximación (conceptual y normativa) del patrimonio natural y cultural (Aplin, 2002; Francioni \& Lenzerini, 2008); b) creando tipologías patrimoniales nuevas muy vinculadas en sus valores a los territorios (patrimonio inmaterial, paisajes culturales, etcétera; Galindo \& Sabaté Bel, 2009); c) exigiendo la delimitación cartográfica precisa de los bienes, tanto en relación con sus zonas núcleo como con el marco territorial en que estas se insertan (buffer zone, áreas de transición, etcétera); y d) propiciando la ampliación de las finalidades de las declaraciones desde una visión estática y centrada en la preservación a la consideración de los bienes patrimoniales como un recurso susceptible de ser utilizado con fines divulgativos, pedagógicos, ambientales y socioeconómicos (Graham, Ashworth \& Tunbridge, 2000; Ortega, 1998).

Respecto al acercamiento del patrimonio al territorio y el cambio de paradigma patrimonial que ello implica, interesa resaltar que este trabajo es producto de varios proyectos de investigación sobre las relaciones patrimonio-territorio-desarrollo sustentados por el Programa Estatal de Fomento de la Investigación Científica y Técnica de Excelencia del Ministerio de Economía y Competitividad de España ${ }^{4}$; de Excelencia de la Junta de Andalucía 5 ; y de la Unión Europea $^{6}$. En 2015 el foco de atención de ese programa derivó hacia el estudio de los paisajes culturales de la Lista del Patrimonio Mundial, en los criterios para identificarlos y en las claves para gestionarlos ${ }^{7}$.

Este artículo se enmarca en estos estudios, pero abre una nueva línea sobre la consideración del territorio en el marco de los programas patrimoniales de la Unesco. Se comulga con el protagonismo creciente del territorio en el contexto de estos programas, pero también se postula,

Referencias: SEJ2006-15331-C02-01; CSO2009-12225-C05-05, CSO2012-39564-C07-07; CSO2015-65787-C6-6-P.

Referencias: P12-SEJ-2024; G-GI3000/IDIO-1563-0284.

Referencia: INV-2016-T/I-001, 2015-2019

Referencia: CSO2015-65787-C6-6-P 
como primer planteamiento básico, que este protagonismo no siempre aparece de manera explícita o como referente claro en sus dictámenes y convenios, por lo que hay que visibilizarlo. La Unesco no ha desarrollado una doctrina precisa en torno al territorio, aunque se puede afirmar que sí ha intuido su importancia. Sus referencias a este son a menudo vagas y no siempre fáciles de identificar por su carácter disperso y fragmentario. Ello explica, aunque no justifica, que las implicaciones y derivaciones territoriales de los programas patrimoniales de la Unesco sean un aspecto que no ha sido tratado a fondo y que urge encarar. Como segundo planteamiento básico, se mantiene que el territorio, aunque motor de buena parte de la renovación conceptual y de la acción protectora y gestora del patrimonio en el marco de la Unesco, presenta desequilibrios en su consideración a causa de que dicha institución lo entiende, o lo malinterpreta, en razón de la propia complejidad del concepto de territorio y de sus significados multidimensionales. Al respecto, este artículo parte de una doble acepción: 1) el territorio entendido como espacio político-administrativo, expresado en unidades gubernamentales con delimitaciones precisas y bien encajadas unas en otras (estados, regiones, administraciones locales); y 2) el territorio físico y cultural, de límites más difusos, resultante de la síntesis entre un soporte natural determinado, unos procesos de construcción histórica y unas dinámicas de percepciones y apropiaciones institucionales y sociales traducidas en leyes, normas y procesos identitarios.

Así, se utiliza el concepto programas patrimoniales territoriales, entendidos estos como aqueIlas iniciativas intergubernamentales auspiciadas por la Unesco a través de convenios y otros textos basados, total o parcialmente, en los valores patrimoniales de los territorios y generadores de listas de bienes con referencia espacial específica y necesariamente definibles, aunque no solo, a través de técnicas cartográficas. De los programas de la Unesco se han desechado aquellos que, o bien no establecen listados, o bien sus referencias espaciales, cuando existen, son imprecisas o ni siquiera son requeridas por la organización. En razón de este criterio, se han seleccionado cuatro programas: la Convención Ramsar (que es el más autónomo y del que la Unesco es solo la depositaria de su texto doctrinal), la Convención para la protección del Patrimonio Mundial Cultural y Natural, el Programa MaB y el Programa Internacional de Geociencias y Geoparques. Tras su identificación, se describen y se comparan en razón del tipo de patrimonio que priorizan (natural o cultural) y de sus finalidades básicas. Ello permitirá conocer, como objetivos principales, la presencia y peso específico de los Estados en las diferentes listas; así como los compromisos que estos asumen y que, a su vez, pueden ser considerados como indicios de sus intenciones e intereses con relación a cada programa. Esto se complementa con la determinación del papel de los Estados (y por ende del territorio político) y de su adscripción regional en la Unesco como condicionante para la aceptación de nuevos bienes en los distintos listados. A tal fin, se abunda en la regionalización de la Unesco de forma crítica respecto a otras divisiones planetarias y se analiza la distribución espacial de los bienes de cada programa patrimonial territorial. El aspecto más innovador del artículo es trabajar con estos cuatro programas de la Unesco de forma simultánea, buscando denominadores comunes, y también asimetrías entre ellos desde la perspectiva territorial y algo consustancial a ella, la asunción del patrimonio como factor de desarrollo.

Además de la bibliografía que se relaciona al final del trabajo, sus principales fuentes han sido los textos documentales de los programas patrimoniales territoriales de la Unesco (www.unesco. org; whc.unesco.org) y del Servicio de Información de Sitios Ramsar (rsis.ramsar.org). 


\section{La Unesco y sus programas patrimoniales territoriales}

La Unesco es la institución internacional más reconocida en cuanto a políticas educativas, científicas y culturales. No es objeto de este artículo valorar la trayectoria de esta organización (véase al respecto su portal web www.unesco.org), pero sí interesa comentar algunas cuestiones que afectan a su proyección en el mundo del patrimonio. De ella se infiere que es una organización con gran peso de la política y que sus interlocutores más directos desde sus inicios (Sewell, 1975) son los 193 Estados a ella adscritos. La grandeza de la Unesco, pero también la mayor fuente de tensiones, es su capacidad de tomar decisiones por mayoría y no sometidas a vetos por países concretos, tal y como sucede en su matriz, las Naciones Unidas (Meskell \& Brumann, 2015). Este carácter más democrático ha impulsado decisiones que, al afectar a los intereses de determinados Estados miembro ha provocado a veces su salida. Especialmente compleja para la organización ha sido la aceptación como Estado miembro de Palestina en 2011, lo que ha motivado que tanto Estados Unidos como Israel hayan decidido dejar la organización. La Unesco es considerada a menudo, en lenguaje coloquial, el verso libre de Naciones Unidas, pero al mismo tiempo ello la legitima como foro abierto entre países dentro de una organización a menudo calificada de poco democrática.

Para la Unesco todos los Estados tienen el mismo peso independientemente de su carácter federal o centralizado y de su extensión, población y riqueza. Este hecho, que en términos políticos tiene una lectura positiva, presenta particularidades desde un punto de vista geográfico y patrimonial. Así, y a título de ejemplo, Estados como Rusia, Chile o China, en toda su diversidad y vastedad computan a efectos prácticos igual que Qatar, Santa Lucía o San Marino lo que hace cuestionable que tengan el mismo trato en términos de casuística patrimonial.

Los programas patrimoniales territoriales de la Unesco son una de las principales expresiones del reconocimiento internacional de bienes culturales o naturales. Se trata de bienes cuya importancia alcanza la escala global y que merecen protección porque su buen mantenimiento interesa al planeta en su conjunto. Los programas más asentados se forjan en los años sesenta y toman carta de naturaleza en el decenio siguiente. Se centran en espacios naturales (Convención Ramsar, Programa Hombre y Biosfera -MaB-) o en elementos culturales o naturales (Convención para la Protección del Patrimonio Cultural y Natural). El programa de la Red Global de Geoparques se institucionaliza en 2015; pese a su sesgo aparentemente centrado en lo natural, se orienta sin embargo al desarrollo de determinadas zonas en las que se valoran también sus bienes culturales.

Todos estos programas patrimoniales territoriales son bien conocidos $y$, por separado, han sido objeto de numerosos análisis (Gardner \& Davidson, 2011; Ishwaran, Persic \& Tri, 2008; MeskeII, 2013; Sánchez-Cortez \& Simbaña-Tasiguano, 2019). Su tratamiento conjunto resulta poco habitual, aunque no es infrecuente que distintos programas confluyan en un mismo territorio y que la propia Unesco aliente su entendimiento conjunto (McInnes, Ali \& Pritchard, 2017).

El primer programa patrimonial territorial intergubernamental, que es autónomo y del que la Unesco es solo depositaria de su tratado, es la Convención Relativa a los Humedales de Importancia Internacional o Convención Ramsar (1971), que se conforman en red y que surge de un tratado referido al patrimonio natural, más específicamente a los hábitats de las aves acuáticas. Pero este sesgo natural no implica la negación del género humano; de hecho, el convenio incluye entre 
sus objetivos «la conservación y el uso racional de los humedales mediante acciones locales, regionales y nacionales y gracias a la cooperación internacional, como contribución al logro de un desarrollo sostenible en todo el mundo» (Ramsar, 2010, s/p). La convención se gestiona por las Conferencias de Partes contratantes (los 170 Estados firmantes), que son su órgano gestor y se reúnen trienalmente. En el período entre conferencias, existe un Comité Permanente que se reúne una vez al año.

En 1972 aparecen dos de las iniciativas más importantes del acervo patrimonial de la Unesco: el Programa sobre el Hombre y la Biosfera -MaB-, del que emana la Red de Reservas de la Biosfera, y la Convención para la Protección del Patrimonio Mundial Cultural y Natural, de la que deriva la Lista del Patrimonio Mundial. El objeto del programa MaB son los ecosistemas valiosos en razón de su biodiversidad, y cuya conservación y uso sostenibles se promueven a través de los lugares adscritos a la Red de Reservas de la Biosfera. La gestión se lleva a cabo a partir del Director General de la Unesco y del Consejo de Coordinación Internacional (MaB-ICC)

La Convención del Patrimonio Mundial, alentada a partir de varias iniciativas de cooperación internacional de los años sesenta presenta en sus inicios, aunque no en sus planteamientos básicos, un sesgo cultural, monumental y urbano, para abrirse luego a lo natural y a escalas territoriales más amplias a través los bienes mixtos y de los paisajes culturales (Fernández Salinas y Silva Pérez, 2016). También ha evolucionado la intención por la que introducir un bien en la Lista, desde su preservación a su utilización como distintivo de excelencia y, por ende, también de marca turística (Navarro, 2015). Su gestión corresponde al Comité del Patrimonio Mundial (compuesto por 21 Estados parte renovables parcialmente cada tres años) que se reúne anualmente para aceptar nuevas candidaturas y revisar los problemas sobrevenidos y otras circunstancias (ampliaciones, revisiones de límites, etcétera) referidas a los bienes ya incluidos.

El último de los programas patrimoniales territoriales de la Unesco, el de Geociencias y Geoparques, data de 2015. Es el primer programa de rango internacional centrado específicamente en el patrimonio geológico y su concreción espacial es la Red Global de Geoparques, cuyos Estados miembro se reúnen anualmente en las conferencias internacionales de los Geoparques Globales de la Unesco. No se trata, no obstante, de un programa nuevo, sino de que la Unesco lo articula a partir de dos redes previamente existentes (la Red de Geoparques Europeos, constituida en 2000, y la Red Global de Geoparques Nacionales, surgida en 2004 en China), confiriéndole un carácter mundial. En cuanto a fines, surge con la intención de alentar el desarrollo de los territorios, esgrimiendo una visión holística e integradora del patrimonio; es el único programa de la Unesco que, de forma expresa, se refiere al uso turístico de los bienes (Unesco, 2015).

Aunque distintos en cuanto a concepciones y planteamientos, los programas anteriores comparten rasgos comunes que los están haciendo converger. De hecho, la Unesco presenta aquellos que son de su manejo más directo (Reservas de la Biosfera, Patrimonio Mundial y Geoparques) como si formasen una "fotografía completa" de biología, cultura y geología (Unesco, 2015, s/p). En todos ellos el territorio es un componente básico a la hora de identificar, proteger y gestionar los bienes y lugares que forman parte de sus registros. La simbiosis entre género humano y naturaleza y la mirada conjunta al patrimonio cultural y natural, aunque con matices en cada programa, es otro rasgo común. En cuanto a fines, todos conjugan la preservación con el desarrollo, aunque también con matices diferenciadores. Contrariamente a lo que cabría esperar, son los programas 
enfocados al patrimonio natural los que con mayor nitidez incorporan en sus articulados objetivos de desarrollo. La Convención Ramsar combina la conservación de humedales y aves acuáticas con el desarrollo sostenible de los territorios que los albergan. El programa MaB asocia la conservación de la biodiversidad con la utilización de los bienes naturales y culturales como instrumentos para la mejora del bienestar de las poblaciones y la reducción de la pobreza. El programa de Geoparques Mundiales surge con la intención de aunar, en pro del desarrollo de los territorios, las declaraciones de Geoparques con las de Reserva de la Biosfera y con los bienes del Patrimonio Mundial. Se erige, en razón de ello, en el exponente más elaborado del acercamiento y progresiva asimilación de los programas patrimoniales territoriales (Schaaf \& Rodrigues, 2016).

La Convención para la Protección del Patrimonio Mundial Cultural y Natural y las consecutivas directrices prácticas para su aplicación, aunque no eluden los fines divulgativos y de desarrollo, priorizan los objetivos de identificación, preservación y salvaguardia frente a los de utilización de los bienes. Pero ello solo sobre el papel, ya que a efectos prácticos se impone muy frecuentemente la utilización del patrimonio cultural como una mercancía que exhibir en mercados turísticos muy saturados y homogenizados, ávidos de calidad y diferenciación (Toselli, 2006). Los retornos de las declaraciones en forma de creación de empleo y riqueza en los lugares de destino es un argumento comúnmente esgrimido, pero raramente demostrado con indicadores y estudios empíricos que lo avalen. Entre tanto, las denuncias sobre deterioros y banalizaciones patrimoniales asociadas a un uso turístico desmedido, lejos de poner freno a la turistización, están exportando estos procesos desde las ciudades históricas a otros territorios patrimoniales de elevado valor natural (Cebrián, 2015).

\section{Los Estados como agentes protagonistas del territorio político de la Unesco}

En tanto que organización eminentemente gubernamental, la Unesco entiende el territorio como una realidad político-administrativa. Sus interlocutores inmediatos son los Estados, que se convierten por ello en los agentes protagonistas de la organización. Esta primacía estatal relega los ámbitos locales a actores secundarios; sin embargo, esta realidad tampoco es homogénea y hay programas en los que los territorios y comunidades adquieren un papel más importante que en otros, sobre todo en el impulso de candidaturas.

Los sitios de las listas patrimoniales de la Unesco son ámbitos espaciales concretos, delimitados a escalas urbanas, comarcales o transnacionales. Actúan como depositarios (y en buena medida también como artífices) de los recursos patrimoniales reconocidos por los registros y los beneficiarios más directos del prestigio y la dinámica económica asociada a estos reconocimientos. Pero las decisiones respecto a qué bienes se proponen para su aceptación por la Unesco no recae en estos ámbitos espaciales sino que compete a los Estados. La Unesco ha primado por su carácter gubernamental la patrimonialización de arriba abajo, siguiendo la práctica habitual entre las instituciones del patrimonio (Carrasco \& Saperas, 2012); pero esta dinámica está cambiando de forma notoria en la Red de Geoparques Mundiales. En este programa la iniciativa de propuesta de nuevos bienes recae en los agentes locales que operan en los territorios.

No ha de entenderse, no obstante, que el rol de los Estados respecto a la gestión de los programas patrimoniales territoriales sea siempre el mismo. Cabe diferenciar dos situaciones que 
tienen que ver con las bases reguladoras de estos programas, por una parte, y con las intenciones de los Estados respecto a la inclusión de nuevos bienes en dichos programas, por otra (Cuadro No 1). En ambos casos el sesgo de los programas hacia el patrimonio natural o cultural incorpora también matices diferenciadores. En lo que tiene que ver con las bases reguladoras, la articulación de áreas Ramsar, Reservas de la Biosfera y Geoparques Mundiales en redes interestatales implica un papel más diluido de los Estados como entes decisorios; en la Lista del Patrimonio Mundial el protagonismo de estos es en cambio mucho más nítido.

\section{Cuadro $\mathrm{N}^{\circ} 1$}

Los programas patrimoniales territoriales de la Unesco desde la perspectiva de los Estados

\begin{tabular}{|l|c|l|c|c|c|}
\hline Listado & $\begin{array}{c}\text { Regido por } \\
\text { convenio }\end{array}$ & Compromisos de los Estados & $\begin{array}{c}\text { Estados } \\
\text { firmantes/ } \\
\text { Partici-pantes }\end{array}$ & $\begin{array}{c}\text { Estados con } \\
\text { bienes en } \\
\text { los listados }\end{array}$ & $\begin{array}{c}\text { Número } \\
\text { de bienes }\end{array}$ \\
\hline $\begin{array}{l}\text { Lista } \\
\text { Ramsar }\end{array}$ & Sí & $\begin{array}{l}\text { Incluir al menos un humedal y } \\
\text { uso racional de los humedales } \\
\text { basado en su sostenibilidad }\end{array}$ & 170 & 170 & $\begin{array}{c}2.370 \\
(2019)\end{array}$ \\
\hline $\begin{array}{l}\text { Red de } \\
\text { Reservas de } \\
\text { la Biosfera }\end{array}$ & No & $\begin{array}{l}\text { Mejorar la relación entre gé- } \\
\text { nero humano y su entorno a } \\
\text { través de la investigación y } \\
\text { gestión sostenible de los re- } \\
\text { cursos de estas reservas }\end{array}$ & $123^{8}$ & 123 & $\begin{array}{c}680 \\
\text { Lista del } \\
\text { Patrimonio } \\
\text { Mundial } \\
\text { Cultural y } \\
\text { Natural }\end{array}$ \\
\hline $\begin{array}{l}\text { Red } \\
\text { Global de } \\
\text { Geoparques }\end{array}$ & No & $\begin{array}{l}\text { Identificar, tutelar y activar el } \\
\text { patrimonio cultural y natural } \\
\text { con valor universal excepcio- } \\
\text { nal }\end{array}$ & 193 & 167 & 1.121 \\
\hline
\end{tabular}

Fuente: Elaboración propia a partir de los portales de Ramsar (https://rsis.ramsar.org) y de la Unesco (www.unesco.org)

Otro rasgo diferenciador del papel de los Estados respecto a la gestión de los programas patrimoniales territoriales tiene que ver con los compromisos adquiridos. También aquí cabe distinguir dos grandes grupos dependiendo del sesgo natural o cultural de cada lista. La incorporación a los programas enfocados al patrimonio natural suele percibirse por los Estados como un acto de responsabilidad. Para integrarse en la red Ramsar se debe proponer al menos un humedal al sistema y también adquirir el compromiso de velar por el mantenimiento de los humedales presentes en sus territorios. En el programa MaB, los Estados son los garantes del mantenimiento de los valores de la red y, en caso de pérdidas o deterioros de tales valores, son los propios Estados quienes

El programa señala que hay 701 reserva en 124 países y no las 680 reales; esto se debe a que una reserva transnacional es computada tantas veces como países en los que se extiende. 
solicitan la retirada de la red. La salida del sistema de Geoparques Mundiales por incumplimientos o pérdidas de valores es una práctica ya habitual en la corta andadura del programa. En cambio, en la Lista del Patrimonio Mundial, balanceada en su praxis al patrimonio cultural, la inclusión de nuevos bienes es vista por los Estados como una oportunidad para la utilización de ese patrimonio como fuente de generación de riqueza y empleo y todos los Estados aspiran a acrecentar el número de sus bienes en ella. En caso de pérdida de valores, las solicitudes de abandono nunca parten de los Estados; es más, resulta muy poco habitual que se salga de esta Lista una vez que se consigue entrar en ella y ello a pesar de la existencia de una Lista de Bienes en Peligro paralela.

La percepción generalizada de que la presencia en la Lista del Patrimonio Mundial es un marchamo de calidad patrimonial susceptible de ser utilizado con fines turísticos ha impulsado el crecimiento acelerado de los registros (de 335 bienes en 1990 se ha pasado a 1.121 en 2019), socavándose con ello dos de los principios rectores de una distinción patrimonial del más elevado nivel: la excepcionalidad y la exclusividad. Para poner freno a ese desfase, La Estrategia Global para una Lista del Patrimonio Mundial Representativa, Equilibrada y Creíble creada por la Unesco en 1994 y medidas posteriores endurecen las condiciones de inscripción, a través de una serie de requisitos limitadores. Para los cometidos de este trabajo interesa resaltar cuatro de esos requerimientos: la recomendación a los países con una mayor representación en la Lista de que espacien las nuevas candidaturas; la limitación a una candidatura anual por parte de los Estados desde 2018; la fijación de un máximo de 35 propuestas para su evaluación anual; y la prioridad dada a las propuestas de países con menos bienes y las regiones y subregiones menos representadas, como África, Pacífico o El Caribe (parágrafo 61 de las Directrices Prácticas sobre la Aplicación de la Convención del Patrimonio Mundial). Tales limitaciones avivan la competencia entre los Estados (y dentro de ellos: entre ciudades y territorios). Una de las pocas diferencias que la Unesco confiere a los Estados a efectos de aceptación de nuevos bienes patrimoniales en esta Lista del Patrimonio Mundial tiene que ver con la región planetaria a la que dichos Estados se adscriben (ver más adelante).

El rol diferenciado de los Estados respecto a la gestión de los programas patrimoniales territoriales y el interés de estos por acrecentar el número de sus bienes en las distintas listas encuentra un correlato en la diferente afección territorial de los programas (Cuadro $N^{\circ} 2$ 2). De los 193 Estados que conforman la Unesco en 2019, no todos ellos han suscrito o cuentan con bienes en las diferentes listas. Cinco Estados (3,59\% del total) carecen de bienes en todas estas listas (Brunei, Guayana, Niue, San Vicente y las Granadinas y Timor Oriental) y, en cambio, $42(21,76 \%)$ tienen bienes en todas ellas. Los dos programas con mayor aceptación son el Convención Ramsar (2.370 áreas en 170 Estados) y la Convención del Patrimonio Mundial Cultural y Natural (1.121 bienes en 167 Estados). En el otro extremo está el Programa de Geoparques Mundiales (147 bienes en 41 Estados), pero hay que tener en cuenta que es un programa de creación muy reciente y que su número de incorporaciones está creciendo muy rápidamente.

\section{Las regiones planetarias como marco analítico y referente de acceso a los programas}

A efectos analíticos y de gestión patrimonial la Unesco organiza los Estados en regiones planetarias. Los programas enfocados al patrimonio natural suelen tener como referencia las regiones biogeográficas para la estructuración del planeta en áreas homogéneas y de sesgo físico. Pero 
dicha estructuración es solo a efectos analíticos y no repercute en la gestión de los programas patrimoniales territoriales por parte de la organización. Para esto último la Unesco recurre habitualmente a una división del planeta propia que lo divide en cinco grandes regiones (que es la que aparece en sus documentos básicos y aglutina a los Estados dentro de ellas). La Figura $N^{\circ} 1$ y el Cuadro $N^{\circ} 2$ la recogen, junto con algunos datos básicos de cada región.

Figura No 1

Las regiones planetarias de la Unesco.

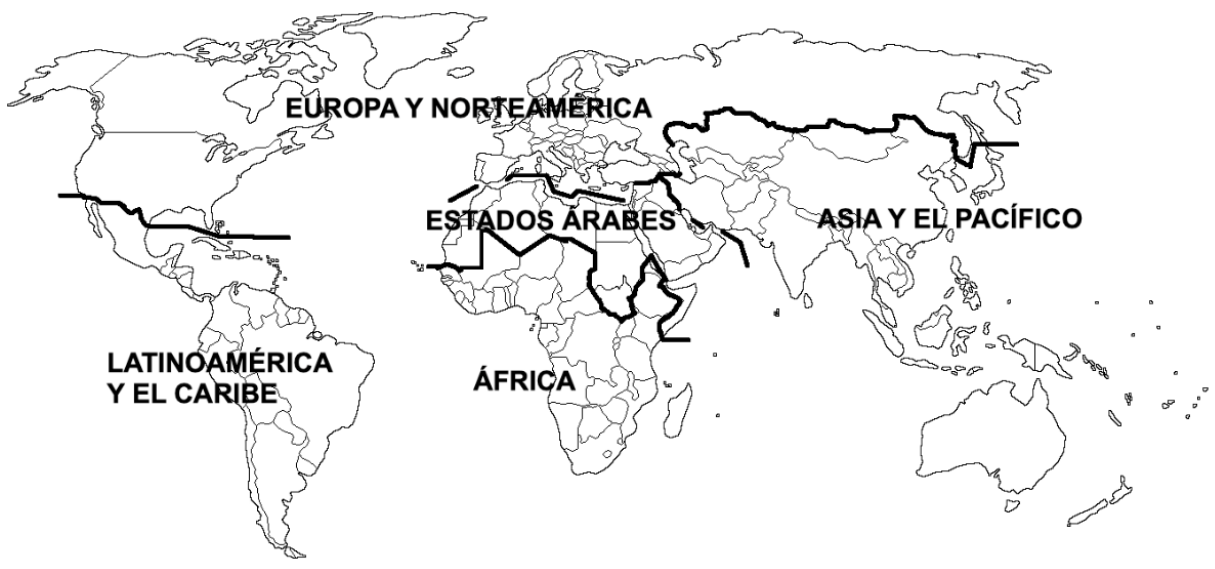

Fuente: Elaboración propia a partir del Servicio de Información sobre Sitios Ramsar (rsis.ramsar.org)

Cuadro No 2

Las regiones planetarias según superficial, población y bienes reconocidos por los programas patrimoniales territoriales de la Unesco

\begin{tabular}{|c|c|c|c|c|c|}
\hline \multirow[b]{2}{*}{ Extensión $\left(\mathrm{km}^{2}\right)$} & \multirow[b]{2}{*}{ Población } & \multicolumn{4}{|c|}{ Bienes reconocidos por programa (total y porcentaje) } \\
\hline & & $\begin{array}{c}\text { Humedales } \\
\text { Ramsar }\end{array}$ & $\begin{array}{c}\text { Reservas de la } \\
\text { Biosfera }\end{array}$ & $\begin{array}{c}\text { Lista del } \\
\text { Patrimonio } \\
\text { Mundial }\end{array}$ & $\begin{array}{c}\text { Red de } \\
\text { Geoparques } \\
\text { Mundiales }\end{array}$ \\
\hline \multicolumn{6}{|c|}{ África } \\
\hline 20.713 .046 & 687.407 .466 & 269 & 76 & 96 & 1 \\
\hline $13,36 \%$ & $9,37 \%$ & $11,35 \%$ & $11,18 \%$ & $8,56 \%$ & $0,68 \%$ \\
\hline \multicolumn{6}{|c|}{ Asia y El Pacífico } \\
\hline 35.594 .364 & 4.126.176.206 & 396 & 157 & 268 & 60 \\
\hline $22,96 \%$ & $56,22 \%$ & $16,71 \%$ & $23,09 \%$ & $23,91 \%$ & $40,82 \%$ \\
\hline \multicolumn{6}{|c|}{ Estados Árabes } \\
\hline 14.438 .569 & 452.390 .210 & 168 & 33 & 86 & 1 \\
\hline $9,31 \%$ & $6,16 \%$ & $7,09 \%$ & $4,85 \%$ & $7,67 \%$ & $0,68 \%$ \\
\hline \multicolumn{6}{|c|}{ Europa y Norteamérica } \\
\hline 63.707 .275 & 1.447.017.641 & 1.191 & 288 & 529 & 78 \\
\hline $41,10 \%$ & $19,72 \%$ & $50,25 \%$ & $42,35 \%$ & $47,19 \%$ & $53,06 \%$ \\
\hline \multicolumn{6}{|c|}{ Latinoamérica y El Caribe } \\
\hline 20.567 .550 & 626.158 .497 & 346 & 126 & 142 & 7 \\
\hline $13,27 \%$ & $8,53 \%$ & $14,60 \%$ & $18,53 \%$ & $12,67 \%$ & $4,76 \%$ \\
\hline
\end{tabular}




\begin{tabular}{|c|c|c|c|c|c|}
\hline \multirow{2}{*}{ Extensión $\left(\mathrm{km}^{2}\right)$} & \multicolumn{2}{|c|}{ Bienes reconocidos por programa (total y porcentaje) } \\
\cline { 3 - 6 } & Población & $\begin{array}{c}\text { Humedales } \\
\text { Ramsar }\end{array}$ & $\begin{array}{c}\text { Reservas de la } \\
\text { Biosfera }\end{array}$ & $\begin{array}{c}\text { Lista del } \\
\text { Patrimonio } \\
\text { Mundial }\end{array}$ & $\begin{array}{c}\text { Red de } \\
\text { Geoparques } \\
\text { Mundiales }\end{array}$ \\
\hline 155.020 .804 & 7.339 .150 .020 & 2.370 & 680 & 1.121 & 147 \\
\hline $100 \%$ & $100 \%$ & $100 \%$ & $100 \%$ & $100 \%$ & $100 \%$ \\
\hline
\end{tabular}

Fuente: Elaboración propia a partir del Servicio de Información sobre Sitios Ramsar (rsis.ramsar.org) y del portal de la Unesco (www.unesco.org)

Esta división no se corresponde con los cinco continentes y tampoco guarda una relación ortodoxa con el mundo político o con el territorio físico y cultural. Al respecto, se puede destacar que:

a) Lo que se entiende por África (casi 21 millones de kilómetros cuadrados y una población cercana a los 700 millones de habitantes) no es el continente en su totalidad, sino su zona subsahariana; o sea, aquella parte caracterizada por el abigarramiento de expresiones culturales y que fue reorganizada por los procesos de descolonización establecidos desde Europa. Existe sin duda una parte común que unifica estas culturas, pero también hay en este ámbito una importante variedad de situaciones sociopolíticas, además de los rasgos culturales subregionales, que la convierten en uno de los espacios más complejos del planeta y en el que conviven países con estructuras muy endebles y situaciones de emergencia social (Liberia, Eritrea, Burundi, etcétera) con otros en los que, a pesar de registrar realidades sociales también difíciles, poseen una situación muy diferente (Islas Seychelles, Sudáfrica o Botsuana).

b) Asia y El Pacífico abarcan un amplio y variado espacio (más de 35,5 millones de kilómetros cuadrados y más de la mitad de la humanidad: por encima de los 4.100 millones de personas) en el que se confunden dos continentes: Asia (con la notabilísima excepción de algunos países árabes y Siberia) y Oceanía. Se trata de la zona mundial sometida a cambios culturales y socioeconómicos más profundos durante los últimos decenios. La inserción en esta región planetaria de Australia y Nueva Zelanda responde a razones de ubicación geográfica más que culturales.

c) La región de los Estados Árabes (más de 14 millones de kilómetros cuadrados y una población que supera los 450 millones de individuos) incluye países del norte de África, del Oriente Próximo y del centro de Asia. Aunque la preponderancia de la religión islámica homogeniza este basto espacio, las diferencias internas, no solo de raza, aunque predomine la árabe, también imprimen profundas desigualdades entre sus Estados, tanto por rasgos geográficos, como socioeconómicos.

d) Europa y Norteamérica, que pese a este último calificativo no incluye México y sí en cambio Siberia, es la región más extensa (casi 65 millones de kilómetros cuadrados) y la segunda más poblada (cerca de 1.500 millones de habitantes). La inclusión de la citada Siberia (que paradójicamente ni es Europa, ni es Norteamérica en términos geográficos tradicionales, sí en la consideración de Eurasia como gran continente), con sus más de 13 millones de kilómetros 
cuadrados, refuerza su peso espacial. Esta región abarca los países más ligados a la cultura occidental, que no los únicos, y que componen una amplia banda del hemisferio norte.

e) Latinoamérica y El Caribe, con sus 20,5 millones de kilómetros cuadrados y más de 600 millones de habitantes, presentan rasgos culturales bastante más homogéneos que los de otras regiones. Allí, las coronas ibéricas conformaron un mundo colonial que ofrece una gran continuidad lingüística y cultural. No obstante, también son importantes, no solo las diferencias físicas (debidas a la conformación de una realidad geográfica norte a sur, frente a la más vigorosa este-oeste predominantes en el más extenso hemisferio norte), sino también las ligadas a diversidad cultural y civilizadora que aparece en amplias zonas, tanto andinas como del Caribe.

Esta regionalización, no tiene el mismo peso en todos los programas patrimoniales territoriales de la Unesco. En algunos solo sirve para diferenciar grandes áreas, sin que ello condicione la entrada en los registros de bienes, como sucede en el programa Ramsar, en el que esta división mundial es menos relevante por tratarse, como ya se ha citado, de un programa en el que la Unesco tiene menos protagonismo en su gestión por ser solo depositaria de su convención; en tanto que en otros sí es un elemento más importante, como es el caso de la Lista del Patrimonio Mundial. En ella, la capacidad de los Estados a la hora de proponer candidaturas varía considerablemente en función de la región planetaria a la que se adscriban. Así, la posibilidad de incorporar nuevos bienes se hace más restrictiva en Europa y Norteamérica por ser la región planetaria que cuenta con más registros; pero habría que tener en cuenta (y no se hace) que también es la región más extensa del planeta, como ya antes ha sido citado, y que alberga Estados con solo uno o dos bienes, como Azerbayán, Irlanda, Islandia, etcétera, que ven limitado, al menos sobre el papel, el acrecentamiento de su número de bienes por el solo hecho de pertenecer a una región que la Unesco entiende como excesivamente representada.

La relación porcentual entre el número de bienes según programas y regiones planetarias y la significación superficial de estas aporta datos interesantes (también incluidos en el Cuadro $\mathrm{N}^{\circ} 2$ ). Europa y Norteamérica es una de las regiones mejor representadas en todos los programas y no solo con relación a la Lista del Patrimonio Mundial antes aludida: el 41,1\% de la superficie plantearía acoge el 50,25\% de los humedales Ramsar; el 42,35\% de las Reservas de la Biosfera; el 47,19\% de los sitios Patrimonio Mundial y el 53,06\% de los Geoparques Globales.

En el otro extremo está África, que es la región planetaria menos reconocida en los diferentes listados patrimoniales territoriales. Con el $13,36 \%$ de la superficie mundial, solo acoge el $11,36 \%$ de los humedales Ramsar; el 11,18\% de las Reservas de la Biosfera; el 8,7\% de los bienes de la Lista del Patrimonio Mundial y el 0,71\% de los Geoparques. La escasa capacidad financiera e institucional de la mayor parte de los Estados africanos (por no mencionar la conflictividad política o la crítica situación humanitaria) para la articulación de nuevas candidaturas y la presentación de propuestas explican en parte este hecho. Dado que los objetivos de desarrollo impregnan hoy todos los programas, se incurre con ello en la paradoja por parte de la Unesco de no dotar de la suficiente visibilidad (o no alentarla suficientemente) a los recursos patrimoniales de una de las regiones del planeta más necesitadas de activación en pro del desarrollo de sus comunidades locales; ello también contrasta con la riqueza, la diversidad, el estado de conservación y la autenticidad de los bienes patrimoniales naturales y culturales de esta parte del planeta, menos banalizada rela- 
tivamente por las secuelas del crecimiento económico ( $y$ eso pese a los deterioros ambientales y disgregación cultural propios de los últimos decenios).

Un comentario particular merece el área de Latinoamérica y El Caribe por el peso relativo que en ella tiene la red de Reservas de la Biosfera: el 18,53\% de los lugares de la red en una superficie que solo representan el $13,27 \%$ de toda la planetaria. El haber sido el origen del concepto de ecodesarrollo (Stenssoro, 2015) y su aplicación en programas de desarrollo que cuentan con la participación de las comunidades locales están detrás de este hecho (Romero, 2009). No es tampoco ajeno a ello el despunte que están teniendo los Geoparques, que aun en un número pequeño (7), están creciendo y creando expectativas interesantes en esta área.

\section{Los programas patrimoniales territoriales de la Unesco según la distribución de sus registros}

La distribución de los humedales Ramsar (Figura $\mathrm{N}^{\circ} 2$ ), pese a ser el registro más independiente de la Unesco, y en principio con menos tensión política, evidencia una destacada presencia de Europa, más allá de la importancia efectiva que tienen sus humedales en el contexto mundial. Otras zonas de interés son Centroamérica, México y El Caribe; el golfo de Guinea, río Congo y parte del Sahel; el extremo oriente (Japón y Corea, sobre todo), y la península indostánica, especialmente en el entorno de alguno de sus grandes ríos (Ganges e Indo); el sudeste asiático y el de Australia. Los grandes vacíos coinciden con los desiertos (pese a que la presencia de humedales localizados en algunos de ellos supone un importante refugio para las aves) y amplias zonas de Rusia (en Siberia son casi testimoniales), Canadá, Estados Unidos, Brasil o Australia. Es cierto que en las latitudes altas el número y especies de aves es menos rico que en otras zonas menos frías, pero no por eso dejan de tener menos importancia estos humedales, especialmente desde que los efectos del calentamiento global se están haciendo bien patentes en las latitudes altas del planeta.

Figura $\mathrm{N}^{\circ} 2$

Distribución de sitios Ramsar

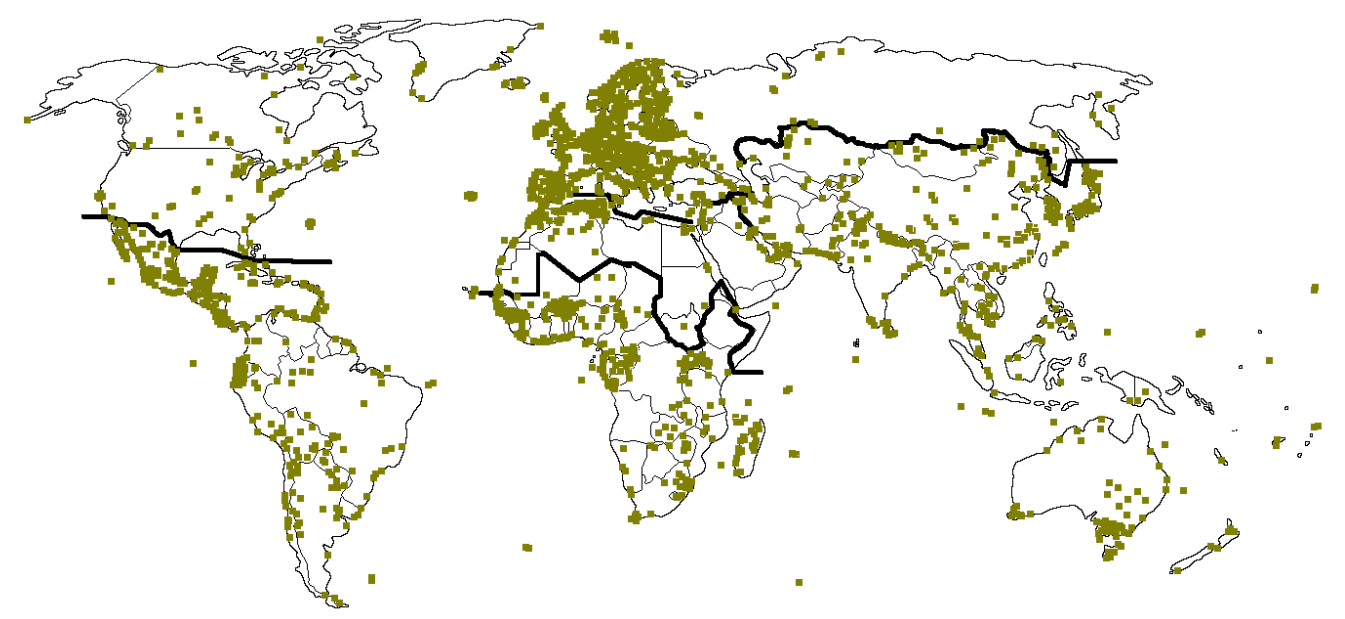

Fuente: Elaboración propia a partir del Servicio de Información sobre Sitios Ramsar (rsis.ramsar.org) 
La distribución de las Reservas de la Biosfera (Figura $N^{\circ} 3$ ) ofrece también similitudes, pese a su número mucho menor que los sitios Ramsar. De nuevo Europa sobresale numéricamente sobre el resto de las partes del planeta. También se repite que algunas zonas que componen la región están muy poco representadas (Siberia, Groenlandia, Canadá y Alaska y el centro-oeste de Estados Unidos). Sin embargo, el hecho de que las iniciativas antes citadas de ecodesarrollo que se implementaron en los últimos decenios del siglo XX surgieran en Iberoamérica, explica una mayor sensibilidad, aunque sea en términos relativos, en esta parte del mundo, sobre todo en Centroamérica, México y El Caribe. Otros espacios de cierta significación son el sudeste asiático y el Sahel occidental.

Figura $\mathrm{N}^{\circ} 3$

Distribución de las Reservas de la Biosfera

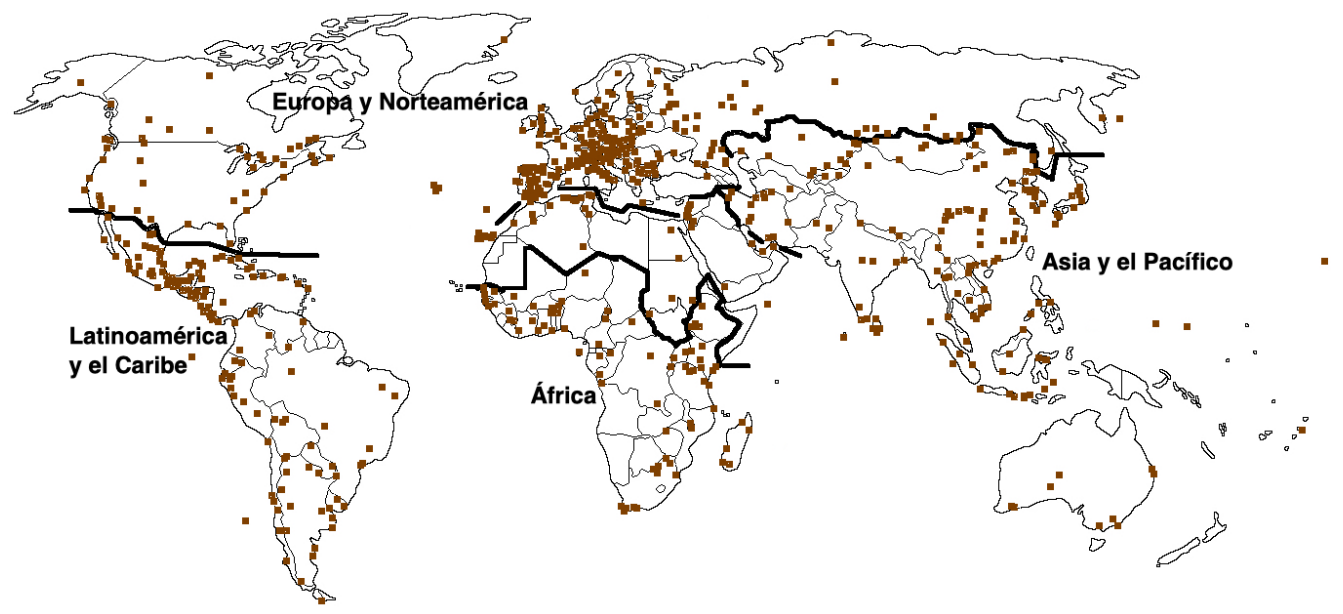

Fuente: Elaboración propia a partir del portal web de la Unesco (www.unesco.org)

El reparto de los sitios inscritos en la Lista del Patrimonio Mundial (Figura $\left.N^{\circ} 4\right)$, el registro que mejor expresa las voluntades e influencias de los Estados, muestra nuevamente el sobrepeso de la representación europea, aunque también se aprecia una concentración de bienes en Centroamérica y El Caribe (que contrasta con los grandes vacíos de Brasil, Argentina y Paraguay, entre otros países) y en los dos extremos del continente asiático. Se repiten los grandes vacíos en Estados Unidos-Canadá, Australia, Amazonía y, sobre todo, Siberia.

Por último, la presencia de los Geoparques Globales, además de ser menos numerosa, también manifiesta una importante concentración dual que se explica por provenir de dos iniciativas en principio independientes: una de varios países europeos y la otra de China (Figura $N^{\circ} 5$ ). Aunque ya han aparecido geoparques en otros lugares del planeta (especialmente en otros países del extremo y sudeste asiático), su manifestación es aún irrelevante, o directamente inexistente (Rusia, Estados Unidos-Canadá, África, Australia, Indostán, etcétera). 
Figura No 4

Distribución de los sitios inscritos en la Lista del Patrimonio Mundial

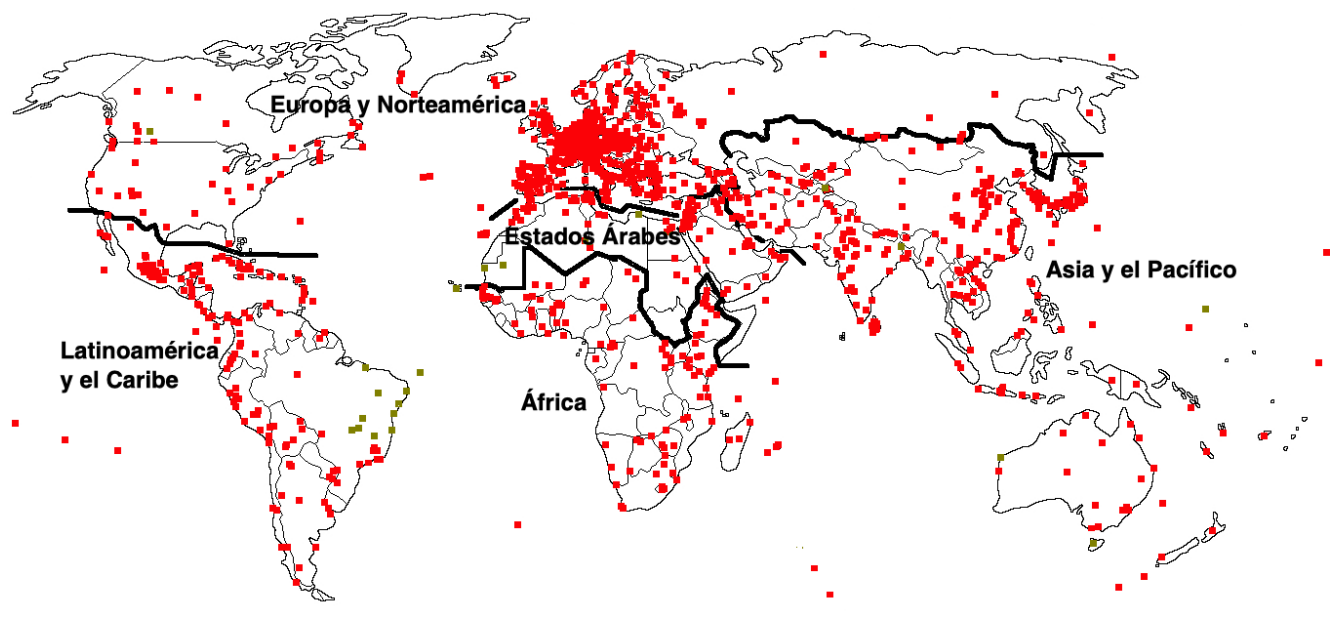

Fuente: Elaboración propia a partir del portal de la página web del Centro del Patrimonio Mundial (whc. unesco.org)

Figura No 5

Distribución de los Geoparques

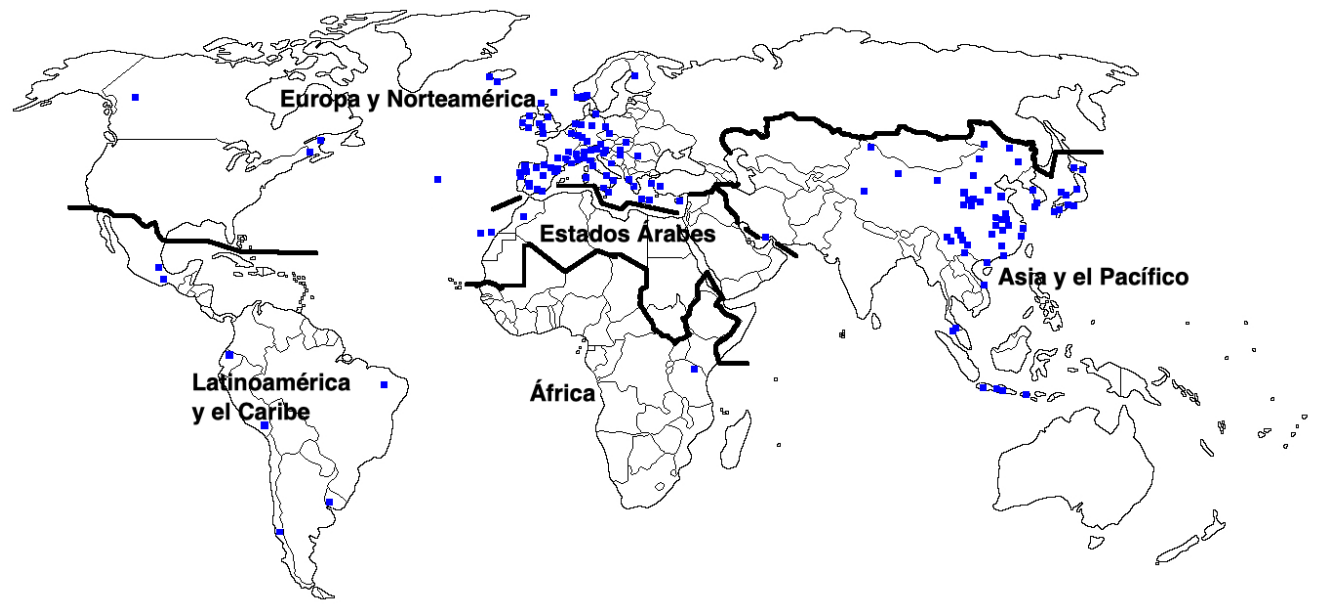

Fuente: Elaboración propia a partir del portal web de la Unesco (www.unesco.org)

\section{Discusión}

El tratamiento conjunto por la literatura especializada de los programas patrimoniales de la Unesco ha sido poco habitual en contraste con la afinidad de sus finalidades y con su creciente coincidencia y solapamiento territorial. Del análisis conjunto se derivan las siguientes consideraciones objeto de discusión: 
a) Unas fuentes de información mejorables:

En este trabajo, uno de sus principales logros e innovaciones, de las el esfuerzo empleado no siempre fácilmente deducible de su lectura, es el de establecer un entendimiento común de los bienes de los programas patrimoniales territoriales de la Unesco. El aparente orden que ofrecen las fuentes ligadas a ellos está trufado de interpretaciones dudosas, duplicidades, imprecisiones de carácter político-administrativo, cuando no de errores en los cómputos y puesta al día de los datos. Esto ha obligado a un minucioso proceso de revisión de listados muy voluminosos (especialmente los de la Lista del Patrimonio Mundial y la Red Ramsar). En este sentido, la Unesco debería acompasar y coordinar su información, máxime en un contexto de convergencia conceptual y de gestión.

b) Un entendimiento del territorio, cuando menos, incompleto:

La Unesco considera el territorio como una armazón política directamente derivada de la estructura de la organización matriz a la que pertenece, las Naciones Unidas. El hecho de que sea una institución bastante autónoma y con criterios propios, no ha facilitado el desarrollo de un planteamiento nítido y preciso en torno al territorio en sus programas patrimoniales territoriales, aunque se puede afirmar que sí se ha percibido su importancia. Sus referencias espaciales son a menudo vagas y no siempre fáciles de identificar por su carácter disperso, fragmentario y soslayado. Ello explica, aunque no justifica, que las implicaciones y derivaciones territoriales de los programas patrimoniales territoriales de la Unesco sean un aspecto que no ha sido tratado a fondo y que a juicio de los autores de este artículo urge impulsar por la relevancia adquirida por el territorio en diversas facetas: a) como condicionante y determinante de la identificación y valoración de los bienes ante los distintos programas patrimoniales territoriales en los que pretenden ser integrados; b) como destinatario de programas patrimoniales específicos, una vez reconocidos, y su relación con el desarrollo de los territorios; y c) como bien de interés patrimonial con categoría sustantiva en nuevas figuras con un calado espacial muy potente (reservas, paisajes culturales, Geoparques, etc.).

En atención a lo anterior, es necesario reforzar los estudios descriptivos de la relación entre los bienes y su espacio; entendiendo este en sus distintas escalas de consideración (inmediata, local, regional, etcétera). Esta descripción no puede ser solo un acercamiento circunstancial al bien $y$, sin solución de continuidad, concretarse en un ámbito de protección, que es la práctica habitual; debe formar parte de su análisis, tanto para la identificación de sus valores, como para la propuesta de su tutela. Esta consideración debe tenerse en cuenta especialmente en el contexto actual de los estudios geográficos, en los que los estadios descriptivos han pasado a un segundo lugar, olvidando que una descripción adecuada es la primera y fundamental parte de cualquier buen análisis espacial. En el caso de la Unesco y sus programas patrimoniales ese análisis espacial debe referirse ineludiblemente también a la escala planetaria: un aspecto que se considera crucial y que a menudo se soslaya.

También hay que enfatizar la conveniencia de utilizar las escalas pequeñas (la planetaria, la de los continentes, la de las regiones de la Unesco, etcétera) como elemento de referencia para la determinación de los programas de la institución. Pese a su vocación universal, las propuestas a listas y registros tienen una plasmación predominantemente local. Nada que 
criticar a este hecho, pero no debe renunciarse a las escalas pequeñas e intermedias como contextos de referencia para la determinación de los valores de los bienes (y no solo para preocuparse por los desequilibrios de representación política de las diferentes áreas que componen el mundo).

c) Los Estados: del orgullo por ser reconocidos en los Listados de la Unesco a la consideración de este hecho como palanca para el desarrollo:

Los Estados, dado el carácter intergubernamental de la Unesco, poseen un papel determinante en el desarrollo de sus programas patrimoniales territoriales (al igual que en otros programas de la organización). Entre ellos han aceptado y firmado convenios y textos, han creado entes para la gestión de los programas y, a pesar de la filosofía más democrática y abierta de la Unesco, no dejan de ejercer su influencia para aprovechar la presencia de sus bienes en los distintos listados.

En los últimos años ha cobrado un particular interés todo lo que tiene que ver con la utilización del patrimonio como motor de desarrollo territorial, aunque excesivamente centrada en la explotación turística de los bienes patrimoniales. Aunque durante los primeros decenios de implementación de los listados derivados de los programas patrimoniales territoriales, estos poseian un aprovechamiento más diverso y generaban sentimientos de afirmación en los espacios atañidos, han pasado a orientarse prioritariamente al uso turístico y, en los últimos años, a la utilización de las distinciones patrimoniales también como reclamo estratégico para la diferenciación territorial en mercados agrarios internacionales cada vez más competitivos y donde la cultura cotiza al alza. En uno y otro caso, amén de pérdidas de autenticidad y deterioros patrimoniales, de ello se deriva una dinámica económica positiva que se traduce en la generación de empleo en el corto-medio plazo; de ahí la competencia de las diferentes instituciones territoriales, especialmente los Estados, por incluir nuevos bienes en los citados registros.

Acompañando estos procesos, cada vez más, los contextos locales se erigen en proponentes (aunque sea a través de los Estados a los que pertenecen) de bienes susceptibles de formar parte de listas patrimoniales de carácter internacional, por un lado, y, por el otro, en responsables inmediatos de la preservación de los valores patrimoniales por los que se accede a dichos registros y de la gestión sostenible de los bienes y sus valores en pro del desarrollo de los territorios.

\section{Conclusiones}

Los programas patrimoniales territoriales de las Unesco entienden el espacio como una matriz de doble entrada: a) la que viene determinada por la proyección cartográfica de los valores de los bienes especificados en sus convenciones y textos, que pese a sus mejoras sigue siendo incompleta, desigual y solo aparentemente sistemática; y b) la que da legitimidad gubernamental a dichos programas y que viene establecida por los Estados como unidad básica de referencia territorial. Es el papel protagonista de estos (diferente en virtud de su influencia política, de su nivel socioeconómico y de su trayectoria en la protección patrimonial) el que explica a) los desequilibrios en las listas entre las distintas regiones del planeta y b) las grandes vacíos mundiales 
sin apenas declaraciones, no tanto por la inexistencia de bienes merecedores de reconocimiento, sino porque a efectos de la Unesco, es mucho menos admisible que haya, por ejemplo, cinco países pequeños signatarios de los programas sin bienes que uno con zonas mucho más bastas también sin ellos, pero que sí cuenta con alguna declaración.

En el futuro debería optarse por regionalizaciones alternativas 0 , mejor, por otros métodos que permitan entender mejor los bienes de los distintos programas patrimoniales territoriales de la Unesco desde las perspectivas globales, especialmente en un contexto de confluencia de estos programas que se abocan, legítimamente, a estrategias de desarrollo territorial. Esto redundará en la mejor gestión y conservación de sus valores y hará repensar a los Estados sobre la forma abusiva y sin criterio con la que a menudo se activan estos bienes en las escalas locales. Habrá que revertir la relación espacial de los programas patrimoniales territoriales de la Unesco en un nuevo encaje global-local que desbarate la forma ya anticuada de considerar el patrimonio, su protección, y asiente vías nuevas para el mantenimiento de sus valores a partir de su activación y retorno social.

\section{Referencias}

APLIN, G. World Heritage Cultural Landscapes. International Journal of Heritage Studies, 2002, No 13 (6), p. 427-446.

CARRASCO, A. \& SAPERAS, E. La Unesco y la institucionalización de la cultura. Razón y Palabra, 2012, No 80, s/p. Disponible en: https://www.redalyc.org/pdf/1995/199524426010.pdf

CEBRIÁN, A.C. Sostenibilidad ambiental y turismo de traspaís en España. Nimbus, 2015, № 11-12, p. 47-66. Disponible en: https://dialnet.unirioja.es/servlet/articulo?codigo=839167

FERNÁNDEZ SALINAS, V. \& SILVA PÉREZ, R. Deconstruyendo los paisajes culturales de la Lista del Patrimonio Mundial de la Unesco. Cuadernos geográficos de la Universidad de Granada, 2016, Vol. 55, No 1, p. 176-197.

FRANCIONI, F. \& LENZERINI, F. The 1972 World Heritage Convention. A commentary. Oxford (Reino Unido): Oxford Univesity Press, 2008.

GALINDO, J. \&; SABATÉ BEL, J. El valor estructurante del patrimonio en la transformación del territorio. Apuntes. Revista de estudios sobre patrimonio cultural, 2009, Vol. 22, № 1, p. 20-33. Disponible en: https://revistas.javeriana.edu.co/index.php/revApuntesArq/article/view/8945

GARDNER, R.C. \& DAVIDSON, N.C. The Ramsar convention. En LEPAGE, B.A. Wetlands: integrating multidisciplinary concepts. Dordrecht (Países Bajos): Springer, 2011. p. 189-203.

GRAHAM, B.; ASHWORTH, G.J. \& TUNBRIDGE, J.E. A Geography of Heritage. Power, Culture and Economy. Nueva York (Estados Unidos): Routledge, 2000 
ISHWARAN, N.; PERSIC, A. \& TRI, N.H. Concept and practice: the case of UNESCO biosphere reserves. International Journal of Environment and Sustainable Development, 2008, Vol. 7, № 2, p. 118-131. Disponible en: http://citeseerx.ist.psu.edu/viewdoc/download?doi=10.1.1.614.235\&rep=rep1\&type=pdf

MCINNES, R.; ALI, K.A. \& PRITCHARD, D. Las convenciones de Ramsar y del Patrimonio Mundial, convergiendo hacia el éxito. Gland (Suiza): Secretaría de la Convención Ramsar, 2017. Disponible en: https://www.ramsar.org/sites/default/files/documents/library/ramsar_whc_converging_ towards_success_s.pdf

MESKELL, L. Unesco's World Heritage Convention at 40: Challenging the economic and political order of international heritage conservation. Current anthropology, 2013, Vol. 54, No 4, p. 483494. Disponible en: https://www.jstor.org/stable/10.1086/671136?seq=1\#metadata_info_tab_contents

MESKELL, L. \& BRUMANN, C. Unesco and New World Orders. En MESKELL, L. Global Heritage: A Reader. Hoboken (Nueva Jersey, Estados Unidos): John Wiley \& Sons, 2015. Disponible en: https:// www.academia.edu/12511580/UNESCO_and_New_World_Orders

NAVARRO, D. Recursos turísticos y atractivos turísticos: conceptualización, clasificación y valoración. Cuadernos de Turismo, 2015, No 35, p. 335-357. Disponible en: https://revistas.um.es/turismo/article/view/221641/173171

ORTEGA, J. El patrimonio territorial: El territorio como recurso cultural y económico. Ciudades, 1998, N. ${ }^{\circ} 4$, p. 31-48.

RAMSAR. Servicio de Información sobre Sitios Ramsar, s.f.. Disponible en: http://rsis.ramsar.org

- Uso racional de los humedales. Gland (Suiza): Ramsar, 2010. Disponible en: https://www.ramsar. org/sites/default/files/documents/pdf/lib/hbk4-01sp.pdf

ROMERO, H. Desarrollo local a escala humana. Polis: Revista Latinoamericana, 2009, N. ${ }^{\circ} 22$, en línea. Disponible en: https://journals.openedition.org/polis/2645

SÁNCHEZ-CORTEZ, J.L. \& SIMBAÑA-TASIGUANO, M. Los geoparques y su implantación en América Latina. Estudios Geográficos, 2019, Vol. 79, № 285, p. 445-467. Disponible en: http://estudiosgeograficos.revistas.csic.es/index.php/estudiosgeograficos/article/view/733

SEWELL, J.P. Unesco and World Politics: Engaging in International Relations. Princeton (Estados Unidos): Princeton University Press, 1975.

SILVA PÉREZ, R. \& FERNÁNDEZ SALINAS, V. El nuevo paradigma del patrimonio y su consideración con los paisajes: Conceptos, métodos y prospectivas. Documents d'Anàlisi Geogràfica, 2017, Vol. 63, No 1, p. 129-151. Disponible en Internet: https://ddd.uab.cat/pub/dag/dag_a2017m1-4v63n1/ dag_a2017v63n1p129.pdf 
SCHAAF, T. \& RODRIGUES, C. Managing MIDAs: Harmonising the Management of Multi-Internationally Designated Areas-Ramsar Sites, World Heritage Sites, Biosphere Reserves and Unesco Global Geoparks. IUCN: Gland (Suiza), 2016. Disponible en: https://www.researchgate.net/publication/312024778_Managing_MIDAS_-_Harmonising_the_management_of_Multi-InternationaIly_Designated_Areas_Ramsar_Sites_World_Heritage_sites_Biosphere_Reserves_and_UNESCO_Global_Geoparks/link/586a3bb608ae329d621015f1/download

STENSSORO, F. El ecodesarrollo como concepto precursor del desarrollo sustentable y su influencia en América Latina. Universum, 2015, Vol. 30, N.0 1, p. 81-99. Disponible en: https://scielo.conicyt.cl/scielo.php?script=sci_arttext\&pid=S0718-23762015000100006

TOSELLI, C. Algunas reflexiones sobre el turismo cultural. Pasos. Revista de turismo y patrimonio cultural, 2006, Vol. 4, N. 2, p. 175-182. Disponible en: http://www.pasosonline.org/Publicados/4206/PS040206.pdf

UNESCO. Programa sobre el Hombre y la Biosfera, MaB. 1971. Disponible en: http://www.unesco. org/new/es/natural-sciences/environment/ecological-sciences/man-and-biosphere-programme/

UNESCO. Convención para la Protección del Patrimonio Mundial Cultural y Natural, 1972. Disponible en: http://portal.unesco.org/es/ev.php-URL_ID=13055\&URL_DO=DO_TOPIC\&URL_SECTION=201.html

UNESCO Programa Internacional de Geociencias y Geoparque, 2015. Disponible en: http://www. unesco.org/new/es/office-in-montevideo/natural-sciences/international-programme-for-geosciences-and-geoparks/ 
